\title{
ПСИХОЛОГИЧЕСКИЕ ОСОБЕННОСТИ КИБЕРБУЛЛИНГА КАК ФОРМЫ ИНТЕРНЕТ-ПРЕСТУПЛЕНИЯ
}

\author{
Елена Александровна Макарова \\ доктор психологических наук, профессор \\ Таганрогский институт управления и экономики \\ 2. Таганрог, Россия \\ E-mail:makarova.h@gmail.com
}

Елена Львовна Макарова кандидат педагогических наук, старший преподаватель Южный федеральный университет (Таганрог) 2. Таганрог, Россия E-mail: h.makarova@gmail.com

\section{Елена Александровна Махрина}

кандидат психологических наук, заведующая каредрой психологии Таганрогский институт им. А. П. Чехова 2. Таганрог, Россия E-mail:mahrina_lena@mail.ru

Целью данной статьи стало исследование проблемы интернет-издевательств в подростковой среде в школе и за ее пределами. Описаны причины, виды и способы совершения актов кибербуллинга. Проанализированы зарубежные исследования, рассматривающие школьное насилие, его особенности, а также связь с агрессивным поведением, показана связь школьного насилия с кибербуллингом, классифицированы последствия его воздействия на психику, поведение подростков, а также на их дальнейшую жизнь и профессиональную деятельность.

В проведенном анкетировании приняли участие 53 студента вуза, которые ответили на вопросы об участии в школьной травле в качестве жертвы или свидетеля, а также сделали предположение о том, кто может прекратить травлю. Интернет представлен как негативная среда для неокрепшей психики подростков, была выявлена необходимость родительского мониторинга деятельности детей в социальных сетях. Намечены возможные пути решения данной проблемы-обоснована необходимость серьезного подхода к данной проблеме, научного исследования различных ее аспектов, 
сделана попытка привлечь внимание научной общественности ксерьезности проблемы. Уделено внимание психологическим последствиям кибербуллинга для всех участников взаимодействия, обоснована необходимость ограничения использования Интернета детьми и подростками и контроля со стороны взрослых. В качестве выводов предложены рекомендации по предотвращению кибербуллинга, а также по ограничению доступа подростков в Интернет, использования мобильной связи. Рекомендации могут быть полезны для школьных учителей и родителей подростков.

Ключевые слова: кибербуллинг, агрессия, депрессия, психологическая травма, уровень эмоционального напряжения, виктимность, суицидальное поведение, родительский контроль, ограниченный доступ, сочиальные сети.

Для цитирования: Макарова Е. А., Макарова Е. Л., Махрина Е. А. Психологические особенности кибербуллинга как формы интернет-преступления // Российский психологический журнал. - 2016. - Т. 13. - № 3. - С. 293-311.

\title{
PSYCHOLOGICAL FEATURES OF CYBERBULLYING AS A FORM OF INTERNET CRIME
}

\author{
Elena Aleksandrovna Makarova \\ Doctor of Psychology, Professor \\ Taganrog Institute of Management and Economics \\ Taganrog, Russia \\ E-mail:makarova.h@gmail.com \\ Elena Lvovna Makarova \\ Candidate of Pedagogy, Senior Lecturer \\ Southern Federal University (Taganrog) \\ Taganrog, Russia \\ E-mail:h.makarova@gmail.com
}

Elena Aleksandrovna Mahrina

Candidate of Psychology, Head of the Department of Psychology Taganrog State Institute named after A. P. Chekhov,

Taganrog, Russia

E-mail:mahrina_lena@mail.ru

The aim of the investigation reported in this paper is to study the problem of Internet bullying among teenagers in and outside of school. The article describes motives, types, and modes of bullying. The authors (a) analyzed foreign studies in the 
field of school bullying and its features, as well as aggressive behavior, (b) showed the connection between school bullying and cyberbullying, and (c) classified the influence of school bullying on teenagers' psychics and behavior, their future life and professional activity.

The empirical study involved 53 high-school students. The respondents answered the questions about school violence (as a victim or a witness), as well as made an assumption about persons responsible for its cease. The Internet was considered to be a harmful environment for the fragile psyche of a teenager. The authors emphasize the necessity of parental monitoring of their children's activities in social nets. The present study (a) offered possible ways of bullying problems solution, (b) explained the necessity of a serious approach to the problem and scientific research of its various aspects, and (c) attempted to attract attention of the scientific community to these urgent issues. The authors paid attention to psychological consequences of cyberbullying for all the participants of interaction and explain the necessity of limiting the access to the Internet and social nets for teenagers, as well as parental monitoring and control. In conclusion, the authors offered recommendations for the prevention of cyberbullying, limitation of Internet access and mobile communication for teenagers. These recommendations are can be useful for school teachers and teenagers' parents.

Keywords: cyberbullying, aggression, depression, psychological trauma, anxiousness, level of emotional tension, victimicity, suicide behavior, parental control, limited access, social networks.

For citation: Makarova E. A., Makarova E. L., Mahrina E. A. Psychological Features of Cyberbullying as a Form of Internet Crime. Russian Psychological Journal, 2016, V. 13, no. 3, pp. 293-311.

\section{Введение}

Школьное насилие, притеснение и травля продолжают беспокоить педагогов и школьных психологов на муниципальном, общенациональном и международном уровнях. Как широко известно, издевательства в образовательной среде стары, как наш мир. Это форма жестокого обращения, нарушения баланса и динамики отношений, когда физически или психологически более сильный подросток получает удовольствие, притесняя слабого и причиняя ему физическую боль или нанося психологическую травму. В понятие «насилие» непременно входят такие составляющие компоненты, как «агрессивные действия» или «агрессия», которые имеют очень важный аспект, т. к. предполагают наличие намерения. Подавляющее большинство исследователей агрессии определяют ее как действие, имеющее своей целью причинение вреда $[9,19]$. Агрессия свойственна каждому человеку, 
т. к. является инстинктивной формой поведения, основной целью которой выступает самозащита и выживание в мире. Все подростки проявляют агрессию в той или иной степени, лишь с возрастом они учатся контролировать агрессивное поведение или скрывать его от окружающих.

\section{Буллинг как форма девиантного поведения}

Однако лонгитюдные исследования показывают, что агрессивность, сложившаяся в детстве, остается устойчивой чертой и сохраняется на протяжении дальнейшей жизни человека. В этих же исследованиях выявляются и описываются уровни агрессивного поведения и влияющие на них факторы, среди которых можно выделить особенности семейного воспитания, образцы агрессивного поведения, которые подросток наблюдает на телеэкране, в компьютерной игре, уровень эмоционального напряжения и фрустрации и т. д. Школьное насилие, таким образом, -это и есть форма проявления повышенной агрессивности по отношению к сверстникам, абсолютно негативное поведение, цель которого-тем или иным способом причинить жертве физический вред или нанести психологическую травму $[2,6,7]$.

Издевательства стары, но их исследования относительно молоды: в 1997 г. впервые начали серьезно изучать эту проблему в США. Тогда лишь в четырех штатах были приняты официальные положения против школьного насилия. Исследователи утверждали, что традиционный буллинг по-прежнему является более распространенным среди молодежи, чем кибербуллинг [12].

Официальный журнал Американской психологической ассоциации выпустил специальный номер, посвященный кибербуллингу, после массового убийства в школе «Колумбайн», где двое учеников старших классов Харрис и Клиболд ранили 37 человек, из них 13 учеников погибли. Полицейское расследование убийств показало, что подростков регулярно подвергали издевательствам в школе, а Харрис еще и подвергался кибербуллингу на сайте, который сам создал, регулярно находил многочисленные оскорбления и угрозы физической расправы. Именно отсюда взял свое начало его нарастающий и неконтролируемый гнев против общества, который привел к таким чудовищным последствиям. В своем дневнике Харрис писал, что он находится в состоянии войны с обществом и бросает ему вызов. Опубликованные в прессе результаты расследования дали начало диалогу и придали проблеме федеральное значение: о школьном буллинге заговорили [15].

Обычно в определениях буллинга отмечается, что он может осуществляться группой лиц или отдельной личностью. Некоторые исследователи по праву считают, что данное явление по определению является групповым процессом [16]. Но все же большинство ученых, как в нашей стране, так и за рубежом, исходят из того, что буллинг может осуществляться как одним, 
так и несколькими лицами [19]. Разумеется, динамика и особенности процесса различны в зависимости от того, идет речь о группе подростков или об одном ученике. Кроме того, одной из главных задач буллинга является управление отношениями (ложная информация, унижение и изоляция) и искажение коммуникации для влияния на жертву в социуме.

Даже один человек может буквально сделать чью-то жизнь кошмаром, заставить ежедневно жить в страхе. В приведенных в литературе определениях также указывается на систематичность действий, т. е. на их регулярную повторяемость на протяжении длительного времени (большинство виновников буллинга - рецидивисты): «Я определяю буллинг как повторяющееся во времени отрицательное по характеру действие по отношению к жертве», «Буллинг среди подростков обычно определяется как преднамеренные повторные действия, обидные слова или другое поведение, такое как угрозы, физический контакт одним по отношению к другому, причем эти негативные действия могут быть непреднамеренно спровоцированы жертвой. Буллинг может быть физическим, вербальным или сексуальным по своей природе» [14, с. 9; 17; 18, с. 1161-1171]. Здесь необходимо подчеркнуть, что любой отдельный эпизод может соответствовать той же схеме и включать в себя те же компоненты, что и повторяющиеся действия [17]. Однако для жертвы буллинга разница между одиночным происшествием и частыми инцидентами неизмерима. Отдельное хулиганство, конечно, может напугать, вызвать напряжение, но непрекращающиеся повторные проявления травли воздействуют глубже, заставляя жертву чувствовать, что так будет всегда, и это вызывает страх и тревогу. Одинаковое гнетущее, парализующее чувство является общим эмоциональным фоном как для страха, так и для тревоги. Разница лишь в том, что страх имеет конкретный источник, вызывающий страх, а тревога-состояние постоянное и беспричинное. Для жертвы буллинга страх входит составной частью в жизнь, ограничивая ее возможности, парализуя инициативу. Один из самых мучительных страхов-социальный, поскольку в любом обществе другие люди играют важную роль, их мнение важно для самооценки и самореализации. Постоянный страх может перерасти в тревожность. Тревожность не зависит от конкретной ситуации и может полностью парализовать нормальную жизнь. В свою очередь, тревожность может спровоцировать страх в ситуациях, в которых другие люди его не испытывают. Страх и тревожность свойственны жертвам буллинга в значительно большей степени, чем остальным подросткам [14, 18].

Школьное насилие -это вид насилия, при котором имеет место принуждение, применение силы. Наряду с физическими и вербальными формами агрессии, нередки случаи социальной изоляции, ее скрытые и тщательно замаскированные проявления слишком часто ускользают от внимания 

3 
(одно международное исследование показало, что сфера его распространения сократилась на $10 \%$ по всему миру), но сбежать от него стало намного сложнее. Интернет проник почти в каждый дом и рабочий офис, не оставляя безопасного места для тех, кто хотел бы от него укрыться.

Хотя кибернасилие не идет ни в какое сравнение с более жестокими преступлениями, такими как вооруженное нападение, изнасилование, похищение людей, но, благодаря анонимности и безнаказанности, оно становится все более опасным и достойным исследования, т. к. причиняет непоправимый вред психологическому здоровью всех участников данного процесса, несмотря на то, что кибербуллинг - более пассивная, но зато более распространенная форма преследования в современной молодежной среде, чем физическое насилие.

Новый уровень буллинга пришел в жизнь благодаря и вместе с легкой доступностью мобильных средств связи, сотовых телефонов, планшетов и компьютерной коммуникации. Издевательства с помощью звонков на мобильные телефоны, текстовых сообщений, интерактивных игр и социальных сетей быстро стали преобладающими формами насильственных действий в пределах школы, но также проникли и в частную жизнь детей школьного возраста, от них не спрятаться в безопасной среде ни в какое время суток.

Кибербуллинг включает в себя «издевательства или домогательства с использованием любого электронного средства, которое может включать в себя электронную почту, обмен сообщениями, блоги, онлайн-игры и вебсайты» [10, с. 2].

Хотя насилие в школе продолжает получать внимание средств массовой информации в течение последних двух лет, кибербуллинг по-прежнему не получает достойного внимания ни в средствах массовой информации, ни в научных кругах, хотя исследования подтверждают, что такого рода травля давно уже перестала быть «детской шалостью» и вносит свою печальную лепту в статистику психических расстройств и подростковых самоубийств.

Издевательства в сети могут быть гораздо хуже, чем в школьном дворе, потому что киберхулиган может скрываться за ником или за анонимной атакой на социальные сети, за неопознанным звонком или сообщением от анонима. Подобно тому, как акты физического насилия ставят под угрозу физическую безопасность, кибербуллинг угрожает психическому здоровью подростков. Анонимность Интернета позволяет хулигану долгое время оставаться безнаказанным, а жертвы кибербуллинга существуют в страхе и тревоге 24 часа в сутки. Выложенное в сеть издевательское заявление, будь то текст или изображение, практически невозможно удалить из киберпространства, особенно если оно размещено на нескольких сайтах. В век новых технологий буллинг тоже приобретает новый уровень. 
Хулиган имеет возможность распространить информацию в Интернете так, что ее просмотрит огромное количество людей, тем самым влияя на общественное мнение, т. е. на психологические механизмы социального восприятия. Это может повлиять на успехи жертв кибербуллинга в учебе, потому что отсутствие уверенности в себе и постоянные насмешки одноклассников мешают им учиться и добиваться успеха. Статистикой подсчитано, что более 61 \% подростков посещают сайты социальных сетей, где они общаются без какого-либо мониторинга со стороны взрослых. Именно на таких сайтах появляются электронные письма с угрозами, демонстрируются компрометирующие или смешные фотографии, сделанные сотовыми телефонами, там же размещаются опросы по поводу этих материалов.

Недавнее исследование, проведенное с помощью провайдера сотовой связи, подтвердило, что оскорбительные СМС-сообщения и электронные письма стали довольно распространенной проблемой среди подростков. В результатах исследования сообщалось, что $87 \%$ опрошенных считают, что в целом изобретение Интернета принесло людям больше хорошего, чем плохого. На другой вопрос $53 \%$ ответили, что их жизнь значительно изменится, если они вдруг лишатся возможности пользоваться Интернетом (по данным фонда «Общественное мнение», 27.01.2016), но при этом 94\% подростков бессистемно просматривают Интернет, 89\% выходят в Интернет из дома, $77 \%$ пользуются связью в школе, $71 \%$ выходят в Сеть от друга или родственника, $66 \%$ - из библиотеки, и $63 \%$ подростков выходят в Интернет ежедневно. Из общего числа опрошенных, 58\% имеют свой сайт в Интернете. Кроме того, исследование показало, что 32 \% подростков имеют некоторый опыт кибербуллинга, т. е. участвовали в нем в той или иной роли, или же были свидетелями. $38 \%$ опрошенных признались, что испытывали страх и огорчение, став жертвой буллинга, а $68 \%$ жертв кибербуллинга рассказали об этом друзьям, родителям. Однако большинство опрошенных подростков не обращали внимания на онлайн-хулиганство, не огорчились, не испытывали страха или замешательства. И, наконец, 32 \% подростков связывались онлайн с совершенно незнакомыми людьми и общались с ними, не сказав своим родителям. По данным за 2010 г., регулярному кибернасилию подверглись $21 \%$ девочек и 22\% мальчиков в возрасте 11 лет; 20\% девочек и $19 \%$ мальчиков в возрасте 13 лет; $12 \%$ девочек и 13\% мальчиков в возрасте 15 лет. Сами регулярно обижали других 24\% мальчиков и 14\% девочек [3].

Исследование, проведенное психологами в США в 2014 г., показало, что $75 \%$ американских подростков подвергались издевательствам онлайн, а 85 \% подвергались издевательствам в школе. В проведенном анонимном телефонном интервью приняли участие 791 подростков в возрасте от 10 до 20 лет (49\% из них - мальчики). 34\% рассказали о 311 случаях 
преследования за прошедший год, $54 \%$ - при личном участии сторон, $15 \%$ с использованием высоких технологий, а 31 \% включали оба вида буллинга. Хотя преследования с использованием технологий включали в себя большое количество свидетелей, как показало исследование, исполнителями в них были анонимы, и этот факт делал преследование менее мучительным, чем то, которое совершалось знакомыми людьми или одноклассниками [11].

Технология предоставила быстрый и безопасный способ для киберхулиганов притеснять своих жертв. Когда родители или взрослые, которые отвечают за детей, зная об издевательствах, не вмешиваются и предоставляют детям самим решать свои проблемы, они как бы говорят, что коварно размещенные на сайте фотографии с оскорбительными комментариями являются приемлемыми, и на них не стоит обращать внимание.

Некоторые взрослые принимают издевательства онлайн как непременную стадию, через которую дети должны пройти, чтобы стать сильными и зрелыми; такое отношение, к сожалению, имеет тенденцию к увеличению. Вопреки таким взглядам, родители и учителя должны проявлять инициативу и действовать вместе, чтобы обеспечить детям большую степень безопасности. В случае попустительства при совершении кибербуллинга, хулиганы получают впечатление, что их поведение санкционировано.

Жертвами кибербуллинга одинаково становятся как девочки, так и мальчики, при этом частота вербальных издевательств и социальной изоляции с возрастом не снижается, а, наоборот, увеличивается, проявляясь особенно активно в подростковом возрасте. Большую роль в проявлениях кибербуллинга играет виктимность, выраженная в особой предрасположенности человека стать жертвой. Повышенная виктимность несовершеннолетних определяется не только их психологическими особенностями, но и социальными ролями, местом в системе социальных отношений, положением, которое они занимают в семье. В социальной психологии свойство виктимности связано с неадекватно заниженной самооценкой, с неспособностью и нежеланием брать на себя ответственность за принятие решений в проблемных ситуациях, с высоким уровнем конформизма, с чувством вины и локусом контроля, и т. д.

Изучение виктимности в психологии выявило у жертв повышенное чувство тревожности, которая рассматривается как эмоционально-личностное образование; жертва принимает установку на беспомощность и ожидает от окружающих сочувствия и жалости [5]. Обычно это-экстернальный тип по локусу контроля, который убежден, что успехи или неудачи являются результатом таких внешних сил, как везение, случайность, давление окружения и т. п. Также виктимность обусловлена низкой самооценкой личности, которая легко поддается принятым в обществе виктимным стереотипам и дает волю 
своим индивидуально-психологическим особенностям: агрессии, конфликтности, тревожности, неуверенности в себе, эмоциональной неустойчивости.

\section{Исследование проблемы}

Теоретический обзор проблемы, анализ отечественных и зарубежных исследований кибербуллинга позволил нам систематизировать психологические характеристики «жертв» и «обидчиков» по следующим показателям: виктимные отношения; коммуникативные способности сторон; враждебность - агрессивность; социометрический статус; эмоционально-психологические особенности; поведение в конфликтной ситуации. Необходимо признать, что исследователи достаточно полно охарактеризовали «жертву» кибербуллинга, незаслуженно обходя вниманием «обидчика», не говоря уже о свидетелях. Данный факт указывает на недостаточную полноту изученности проблемы психологических особенностей участников кибербуллинга, тем самым определяя актуальность нашего исследования.

Принято считать, что организаторами и исполнителями кибербуллинга становятся физически и нравственно сильные, но интеллектуально неразвитые дети, которые таким образом пытаются компенсировать свою интеллектуальную и социальную несостоятельность. На самом деле, так было в эпоху традиционного школьного насилия с его физической составляющей. Чтобы использовать Интернет как орудие буллинга и при этом остаться безнаказанным, необходимы интеллектуальная зрелость и гибкость мышления. Определенная ущербность, конечно, имеется, но другого, психологического характера: нарциссизм, готовность достигать цели любыми способами, отсутствие эмпатии, искаженные моральные принципы, нездоровое стремление к лидерству и дешевой популярности, агрессия, авторитарность, беспринципность и цинизм.

Психологические последствия любого насилия могут проявиться спустя годы. Виктимные подростки, становясь взрослыми, часто страдают бессонницей, психическими расстройствами, склонны к подозрительности, тревожности, депрессивности и суицидальному поведению. Сами «школьные тираны» тоже страдают от психологических последствий своего девиантного поведения: став взрослыми, они имеют очень большие шансы остаться одинокими, т. к. буллинг развивает у них склонность к нарциссизму, догматизм, авторитарность, комплекс превосходства над остальными. Агрессивное поведение в подростковом возрасте нередко приводит к проблемам с социальной адаптацией, например, на работе или в семье.

Не остаются в стороне и свидетели школьной травли -в последующей жизни они могут страдать от эмоционального расстройства, резкого изменения настроения, поведения, нервозности, и испытывать неуверенность в себе. 
Они всю жизнь стремятся к защите своей электронной «жизни», избегают групповых встреч, испытывают нервозность при получении мобильных сообщений или электронной почты, избегают говорить о компьютерах или мобильных телефонах, о средствах защиты информации и авторских правах.

Доказательство этого было получено группой ученых из Королевского колледжа в Лондоне. Наблюдение велось за детьми Англии, Шотландии и Уэльса, которые подвергались насилию в 7 и 11-летнем возрасте, сами участвовали в буллинге или были свидетелями. Затем замеры делались по достижении ими возраста 23, 33, 42, 45 и 50 лет. Подробный отчет о результатах исследования опубликован в Американском психиатрическом журнале [8]. Цифры подтверждают, что жертвы постоянного буллинга в школе, становясь взрослыми, существенно чаще жалуются на здоровье, страдают от депрессии, нервных расстройств и склонны к суициду. Они менее успешны в профессиональной деятельности, у них более низкий доход, выше риск остаться без работы. Они чаще ведут одинокий образ жизни, не имея ни семьи, ни друзей. Иначе говоря, «детские обиды» оборачиваются вполне серьезными взрослыми проблемами. Зная это, родителям стоит внимательнее следить за тем, чтобы их ребенок не стал жертвой буллинга.

\section{Результаты}

В нашем анкетировании принимали участие студенты ТИУиЭ разных лет обучения. Целью анкетирования было привлечь внимание к проблеме, показать ее актуальность, обозначить круг вопросов и собрать базу данных для дальнейшего исследования. Вопросы анкеты были направлены на предыдущий опыт студентов и память о нем. Понятно, что незначительные обиды стираются из памяти, в то время как продолжительный повторяющийся кибербуллинг оставляет след не только в памяти, но и в психике человека. Всего в исследовании приняли участие 53 студента. Из них женщин до 19 лет-13 человек, женщин от 20 лет-20 человек, мужчин до 19 лет-4 человека, мужчин от 20 лет -7 человек, не подписались - 9 человек. Участие в анкетировании было добровольным и анонимным.

37 из 53 опрошенных признались, что были жертвами кибербуллинга, из них $37 \%$ испытывали кибербуллинг довольно часто, 20\% подтвердили, что сталкиваются с буллингом в сети ежедневно. Подтвердилось, что юноши и девушки одинаково подвергаются риску кибербуллинга. Социальная жизнь подростков протекает в социальных сетях, из них Facebook, Twitter, Instagram и U-tube являются наиболее популярными. Из перечисленных соцсетей Facebook и Twitter отмечены как самые благоприятные для кибербуллинга. $54 \%$ подростков, использующих Facebook, подтвердили, что подвергались киберхулиганству в сети. 
RUSSIAN PSYCHOLOGICAL JOURNAL・2016 VOL. 13 \# 3

Сравнивая результаты, мы смогли получить: а) процент подростков, пользующихся социальной сетью; б) процент пользователей соцсети, которые подвергались кибербуллингу. По результатам опроса было выявлено, что кибербуллинг причинил неизгладимый вред самооценке и социальной жизни 70\% молодых людей, принимавших участие в анкетировании.

Согласно проведенному анализу, $75 \%$ опрошенных пользуются соцсетью Facebook, 54\% из них подвергались кибербуллингу; 66\% опрошенных пользуются соцсетью U-tube, 21 \% из них подвергались кибербуллингу; $43 \%$ опрошенных пользуются соцсетью Twitter, $28 \%$ из них подвергались кибербуллингу; 24\% опрошенных пользуются соцсетью Instagram, 24\% из них подвергались кибербуллингу.

При анкетировании респондентов попросили проранжировать влияние кибербуллинга на их жизнь по шкале от 1 до 10 (1-не влияет, 10-оказал очень сильное влияние). На диаграмме приведены среднестатистические данные по всей группе анкетируемых (53 человека).

1. Самооценка $(7,65 / 10)$ - респондентов просили указать, как повлиял кибербуллинг на представление о своей личности, деятельности среди других людей и оценивании себя, собственных качеств и чувств, достоинств и недостатков.

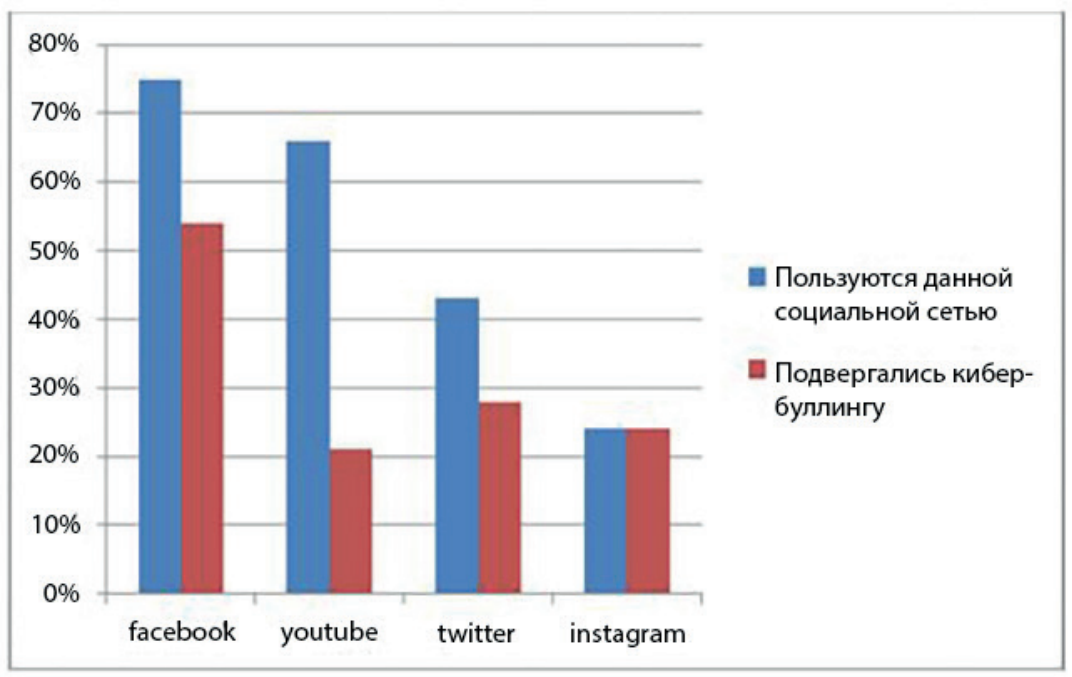

Рисунок 1. Анализ частоты пользования социальными сетями и риска подвергнуться кибербуллингу в этих сетях 


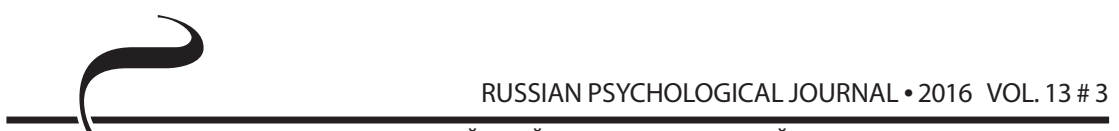

РОССИЙСКИЙ ПСИХОЛОГИЧЕСКИЙ ЖУРНАЛ • 2016 ТОМ 13 № 3

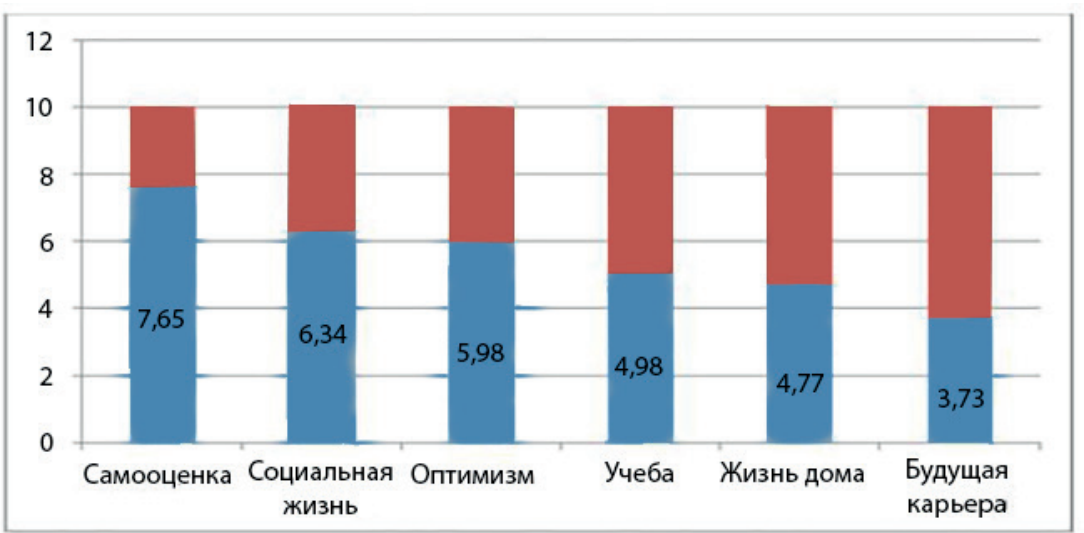

Рисунок 2. Влияние кибербуллинга на жизнь респондентов по шкале от 1 до 10

2. Социальная жизнь (6,34/10) - респондентов просили указать, как повлиял кибербуллинг на их социальную жизнь и социальные навыки. Существует корреляция между кибербуллингом и его пролонгированным воздействием на будущую социальную жизнь жертвы.

3. Оптимизм (5,98/10) - респондентов просили указать, как повлиял кибербуллинг на их представление и мечты о будущем.

4. Учеба $(4,98 / 10)$ - респондентов просили указать, как повлиял кибербуллинг на их учебу и поведение в аудитории.

5. Жизнь дома $(4,77 / 10)$ - респондентов просили указать, как повлиял кибербуллинг на их отношения с членами семьи.

6. Будущая карьера (3,73/10) - респондентов просили указать, как повлиял кибербуллинг на их карьерные планы и выбор дальнейшей профессиональной деятельности.

Кроме соцсетей, подростки активно используют интернет-приложения в своих смартфонах и других мобильных гаджетах. На вопрос анкеты «Какие интернет-приложения вы используете в своем смартфоне?» $68 \%$ опрошенных ответили, что используют Instagram для отправки фото, $67 \%$ опрошенных используют Skyре для видеозвонков, отправки текстовых сообщений, $57 \%$ опрошенных используют WhatsApp для бесплатных сообщений и выхода в Интернет, $13 \%$ опрошенных используют Viber для видео, телефонных звонков, отправки текстовых сообщений.

На вопрос «Для чего вы используете интернет-приложения в своих мобильных гаджетах?» 69\% опрошенных ответили, что используют их для 
RUSSIAN PSYCHOLOGICAL JOURNAL・2016 VOL. 13 \# 3

развлечений, 38\% опрошенных - для приобретения новых друзей, $60 \%$-для связи с семьей и друзьями, 57\% - как дешевое средство для текстовых сообщений и звонков, $12 \%$ - чтобы знакомиться с новыми людьми, $40 \%$-для связи с теми, кого они знают, 39\% - чтобы делиться информацией.

Следующим вопросом анкеты был «Как часто вы используете интернетприложения в своем смартфоне?» (см. таблицу 1 и рисунок 3).

Таблица 1.

Результаты опроса («Как часто вы используете интернет-приложения в своем смартфоне?»)

\begin{tabular}{|c|c|c|c|c|c|}
\hline & $\begin{array}{c}\text { Несколько } \\
\text { раз в день }\end{array}$ & $\begin{array}{c}\text { один раз } \\
\text { в день }\end{array}$ & $\begin{array}{c}\text { Несколько } \\
\text { раз } \\
\text { в неделю }\end{array}$ & $\begin{array}{c}\text { Один раз } \\
\text { в неделю }\end{array}$ & $\begin{array}{c}\text { Время } \\
\text { от времени }\end{array}$ \\
\hline Instagram & $55 \%$ & $15 \%$ & $8 \%$ & $10 \%$ & $3 \%$ \\
\hline Skype & $33 \%$ & $12 \%$ & $15 \%$ & $8 \%$ & $4 \%$ \\
\hline WhatsApp & $47 \%$ & $8 \%$ & $13 \%$ & $6 \%$ & $4 \%$ \\
\hline Viber & $19 \%$ & $3 \%$ & $13 \%$ & $3 \%$ & $5 \%$ \\
\hline
\end{tabular}

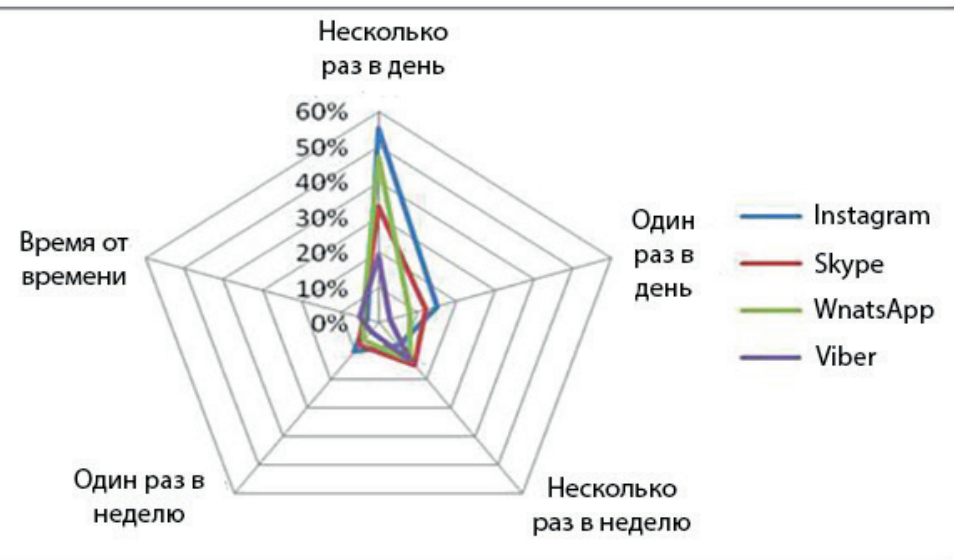

Рисунок 3. «Как часто вы используете интернет-приложения в своем смартфоне?» 
На вопрос «Вы когда-либо получали оскорбительные комментарии на свои фото- или видеоматериалы?» $47 \%$ от всего количества опрошенных ответили «Да», из них 17\% - на Instagram, 13\% - на Skype, 1\% - на Viber, 8\% - на Twitter.

$62 \%$ опрошенных получали оскорбительные сообщения на телефон, из них 9\% - на Instagram, 24\% - на Skype, 2\% - на Viber, 8\% - на Twitter. 28\% подтвердили, что кто-то делился их личной информацией без разрешения, из них $10 \%$ - на Instagram, $10 \%$ - на Skyре, 2\% - на Viber, $2 \%$ - на Twitter. $53 \%$ никому не рассказывали о нежелательных звонках или об оскорблениях в интернетприложениях, $48 \%$ - рассказывали.

На вопрос «Почему вы никому не рассказали о случившемся?» $28 \%$ ответили, что не верили в серьезность происшедшего, 19\% не верили, что их примут всерьез, $11 \%$ рассказывали об этом раньше, но не получили отклика, 10\% боялись, что все станет еще хуже, 10\% вообще не хотели говорить об этом, и $6 \%$ не знали, как и кому можно доверять в этом вопросе.

На вопрос «Что случилось с вами после получения оскорблений или угроз по телефону?» 49\% ответили, что испытали неуверенность в себе, $47 \%$ почувствовали себя в опасности, 38\% пытались изменить что-либо в этой ситуации, $30 \%$ заявили, что кибербуллинг повлиял на их личную жизнь, 28\% признались, что отомстили, $24 \%$ стали винить себя в том, что произошло.

Также как и в других видах буллинга, оскорбления по телефону, как выяснилось по результатам опроса, оказали отрицательное воздействие на самооценку и уверенность в себе у всех опрошенных. Общение по телефону может быть чрезвычайно личным, и в этом случае кибербуллинг может угрожать физическому и эмоциональному здоровью подростков. Значительное количество опрошенных признались, что обвиняли себя в том, что стали жертвой кибербуллинга. Хотя кибербуллинг в телефонных интернет-приложениях совершается в виртуальном пространстве, он имеет значительное влияние на реальную жизнь почти у всех опрошенных, распространяясь на все сферы жизни: от учебы и выбора дальнейшей карьеры до участия в социальной жизни и отношений с семьей.

В ходе опроса обнаружилось, что «замкнутый круг»-это самое подходящее определение для кибербуллинга, каждый из трех подростков отвечал тем, что отправлял оскорбительное сообщение обидчику или кому-то другому. Один их четырех опрошенных обвинял в случившемся себя, это соотношение намного превосходит средние показатели по обычному буллингу.

$47 \%$ написали, что получали неприличные комментарии на фото и видео, которые сами же разместили в соцсетях; такое отношение показывает, что они обвиняют себя и видят проблему тоже в себе. Только 1 из 53 опрошенных после получения оскорбления решил никогда больше не пользоваться интернет-приложениями смартфона. 
По результатам опроса можно сделать следующие выводы: необходимы усилия всех взрослых в школе и дома, чтобы противостоять напору киберхулиганов. Взрослым необходимо объединиться, чтобы информировать и защищать подростков, оградить их от публичного унижения. Взрослые должны знать, что хотя насилие в интернет-среде является сложным вопросом с многочисленными и разнообразными причинами, проблемы кибербуллинга носят длительный характер и требуют систематических усилий для борьбы с ними [7]. Кибербуллинг-это сложный процесс, в котором одинаково участвуют жертвы, преследователи, свидетели, в нем учитывается взаимодействие между участниками, а также позиция взрослых по отношению к происходящему. Для понимания проблемы следует учитывать множество факторов, а не ограничиваться упрощенными представлениями о хулигане и его беспомощной жертве. Любая стратегия вмешательства при кибербуллинге должна быть направлена на процесс в целом; если же исходить при этом из эмпирической модели буллинга, то эффективность вмешательства повышается.

Можно воспользоваться системным подходом для создания безопасной образовательной среды, включая четкие определения явлений, методы преодоления девиантного поведения и новую образовательную политику, которая стремится ограждать и защищать подростков.

В «Уставе Организации Объединенных Наций по правам несовершеннолетних» говорится, что каждый ребенок имеет право на образование и право на свободу от насилия в образовательной среде [4]. Тем не менее, когда речь идет о кибербуллинге, родители и студенты воспринимают его как широко распространенное явление за пределами образовательной среды. Как же тогда приступить к решению этой серьезной проблемы? Школьный персонал обязан создавать и последовательно применять такую политику, которая поможет предотвращать и ликвидировать кибербуллинг среди подростков.

\section{Рекомендации}

Школьный персонал должен реагировать соответствующим образом, когда жалобы на кибербуллинг доводятся до их сведения, и помогать в предотвращении такого рода преступлений. В качестве превентивных мер предлагаются следующие: рассказывать подросткам, что они должны информировать родителей или психолога в случае любого кибербуллинга; информировать родителей и подростков о наказуемости подобных правонарушений и о правовой базе, с этим связанной; поощрять родителей, которые считают обычной практикой проверку текстовых сообщений и фотографий на мобильных телефонах подростков; информировать родителей о доступных услугах, о различных типах программного обеспечения для мониторинга 
и инфо-фильтров; обсуждать с родителями и подростками общие особенности кибербуллинга, поощрять родителей обращаться к провайдеру услуг Интернета за помощью, если кибербуллинг не прекращается; блокировать хулигана - большинство устройств имеют параметры, которые позволяют блокировать электронную почту, мгновенные сообщения или тексты от конкретных людей; осуществлять плановое техническое обслуживание и мониторинг использования компьютеров персоналом и обучаемыми.

\section{Литература}

1. Берг Т. Н. Нервно-психическая неустойчивость и способы ее выявления. - Владивосток: Изд-во Мор. гос. ун-та, 2005.

2. Зиновьева Н. О., Михайлова Н. Ф. «Психология и психотерапия насилия». Ребенок в кризисной ситуации. -СПб.: Речь, 2003.

3. Интернет в России: его значение для россиян, цели и время использования // URL: http://www.bizhit.ru/index/internet_v_rossii_i_ego znachenie/0-593

4. Конвенция о правах ребенка // Сборник международных договоров CCCP. - 1993. - выпуск XLVI. - URL: http://kirovskayasoch.ucoz.ru/ KONVENCIYA_O_PRAVAH_REBENKA.pdf

5. Малкина-Пых И. Г. Психология поведения жертвы. - М.: Эксмо, 2006. 1008 c.

6. Проблемы насилия над детьми и пути их преодоления / Под. ред. Е. Н. Волковой. - СПб.: Питер, 2008. - 240 с.

7. Профилактика школьного буллинга. Методические материалы / Авторсоставитель: А. Ненашева. - Южно-Сахалинск, 2015.

8. Arehart-Treichel J. Effects of Bullying Don't End When School Does // American Journal of Psychiatry. - 2013. -V. 48. - no. 7. - pp. 12-17.

9. Buss A. H. Agression pays // The control of aggression and violence / J. L. Singer (Ed.). - N. Y.: Academic Press, 1971.

10. Center for the Prevention of School Violence, North Carolina Department of Justice and Delinquency Prevention. A Vision for Safer School. - Raleigh, 2000.

11. Hamby S., McDonald R. Trends in violence research // Psychology of Violence. 2014. -V. 4 (1). - pp. 1-7.

12. Media Advisory: American Psychological Association's 120th Annual Convention. Proceedings and Presentations. - Orlando, USA, 2012.

13. Mehari K. R., Farrell A. D., Le Anh-Thuy H. Cyberbullying among adolescents: Measures in search of a construct // Psychology of Violence. - 2014. V. 4 (4). - pp. 399-415.

14. Olweus D. Bullying at School. - Oxford, UK: Blackwell, 1993. - P. 9.

15. Pellegrini A. D., Bartini M., Brooks F. School bullies, victims, and aggressive victims: 
Factors relating to group affiliation and victimization in early adolescence// Journal of Educational Psychology. - 1999. -V. 91 (2). - pp. 216-224.

16. Pikas A. The common concern method for the treatment of mobbing //Bullying: An international perspective / E. Roland, E. Munthe (eds.). - London: David Fulton Publishers, 1989. - pp. 91-104.

17. Roland E. School Influences on Bullying. - Stavanger: Rebell, 1999.

18. Salmivalli C. Prospective Relations among Victimization, Rejection, Friendlessness, and Children's Self- and Peer-Perceptions // Child Development. 2005. - V. 76. - I. 6.

19. Smith P., Waterman M. Sex differences in processing aggression words using the Emotional Stroop task // Aggressive Behavior. - 2005. -V. 31. - I. 3. pp. 271-282.

20. Wigderson S., Lynch M. Cyber- and traditional peer victimization: Unique relationships with adolescent well-being // Psychology of Violence. - 2013. V. 3 (4). - pp. 297-309.

\section{References}

1. Berg T. N. Nervno-psikhicheskaia neustoichivost' i sposoby ee vyiavleniia [Neuropsychic instability and methods of its revelation]. Vladivostok, Moscow State University Publ., 2005.

2. Zinov'eva N. O., Mikhailova N. F. «Psikhologiia i psikhoterapiia nasiliia». Rebenok v krizisnoi situatsii ["The psychology and psychotherapy of violence". A child in a crisis situation]. St. Petersburg, Rech' Publ., 2003.

3. The internet in Russia: its significance for Russians, purposes and time of using. Available at: http://www.bizhit.ru/index/internet_v_rossii_i_ego_ znachenie/0-593

4. The convention on the rights of the child: Collection of international treaties of the USSR, 1993, XLVI edition. Available at: http://kirovskayasoch.ucoz.ru/ KONVENCIYA_O_PRAVAH_REBENKA.pdf

5. Malkina-Pykh I. G. Psikhologiia povedeniia zhertvy [The psychology of the victim's behavior]. Moscow, Eksmo Publ., 2006. 1008 p.

6. Volkova E. N. Problemy nasiliia nad det'mi i puti ikh preodoleniia [The problem of child abuse and ways of its overcoming]. St. Petersburg, Piter Publ., 2008. 240 p.

7. Nenasheva A. Profilaktika shkol'nogo bullinga [Prevention of school bullying]. luzhno-Sakhalinsk, 2015.

8. Arehart-Treichel J. Effects of Bullying Don't End When School Does. American Journal of Psychiatry, 2013, V. 48, no. 7, pp. 12-17.

9. Buss A. H. Agression pays. The control of aggression and violence. J. L. Singer (Ed.). N. Y.: Academic Press, 1971. 
10. Center for the Prevention of School Violence, North Carolina Department of Justice and Delinquency Prevention. A Vision for Safer School. Raleigh, 2000.

11. Hamby S., McDonald R. Trends in violence research. Psychology of Violence, 2014, V. 4 (1), pp. 1-7.

12. Media Advisory: American Psychological Association's 120th Annual Convention. Proceedings and Presentations. Orlando, USA, 2012.

13. Mehari K. R., Farrell A. D., Le Anh-Thuy H. Cyberbullying among adolescents: Measures in search of a construct. Psychology of Violence, 2014, V. 4 (4), pp. 399-415.

14. Olweus D. Bullying at School. Oxford, UK: Blackwell, 1993, P. 9.

15. Pellegrini A. D., Bartini M., Brooks F. School bullies, victims, and aggressive victims: Factors relating to group affiliation and victimization in early adolescence. Journal of Educational Psychology, 1999, V. 91 (2), pp. 216-224.

16. Pikas A. The common concern method for the treatment of mobbing. Bullying: An international perspective. E. Roland, E. Munthe (eds.). London: David Fulton Publishers, 1989, pp. 91-104.

17. Roland E. School Influences on Bullying. Stavanger: Rebell, 1999.

18. Salmivalli C. Prospective Relations among Victimization, Rejection, Friendlessness, and Children's Self- and Peer-Perceptions. Child Development, 2005, V. 76, I. 6.

19. Smith P., Waterman M. Sex differences in processing aggression words using the Emotional Stroop task. Aggressive Behavior, 2005, V. 31, I. 3, pp. 271-282.

20. Wigderson S., Lynch M. Cyber- and traditional peer victimization: Unique relationships with adolescent well-being. Psychology of Violence, 2013, V. 3 (4), pp. 297-309. 